\section{Does Inflation Targeting Matter?}

\author{
Manfred J.M. Neumann and Jürgen von Hagen
}

\section{INTRODUCTION}

$\mathbf{S}$ ince it was first introduced by New Zealand and Chile in 1990, Canada in 1991, and the United Kingdom in 1992, inflation targeting (IT) has received a lot of attention in the public and academic debate over the design of monetary policy regimes. In part, this attention reflects the growing number of countries that have adopted an IT regime over the past decade. Schaechter, Stone, and Zelmer (2000) count 13 countries with IT experience as of February 2000: Australia, Brazil, Canada, Chile, the Czech Republic, Finland, Israel, New Zealand, Poland, South Africa, Spain, Sweden, and the United Kingdom. Corbo, Landerretche Moreno, and Schmidt-Hebbel (2001) add Korea and Thailand to this list. Most recently, Hungary and Switzerland have introduced inflation targets. Since the Bundesbank declared a normative target inflation rate as the principal goal of its monetary policy, Mishkin and Posen (1997), following von Hagen (1995), classify Germany as an early case of IT, although the German inflation objective was formulated for the medium run, while the short-run focus of the Bundesbank's monetary strategy was on the annual monetary target.

As early as 1994, an academic conference reviewed the experience with IT (Leiderman and Svensson, 1995). A number of more recent studies summarize the experience gained with IT over the past decade (Bernanke et al., 1999; Corbo, Landerretche Moreno, and Schmidt-Hebbel, 2001). These papers focus on a variety of questions related to the choice of monetary regimes, including the improvement in inflation performance, in monetary

Manfred J.M. Neumann is a professor of economics at the University of Bonn and a member of the Academic Advisory Council of the German Federal Ministry of Economics and of the Bundesbank's Research Advisory Council. Jürgen von Hagen is a professor of economics and director of the Center for European Integration Studies at the University of Bonn, a research fellow of CEPR, and a member of the Academic Advisory Council of the Federal Ministry of Economics, the Bundesbank's Research Advisory Council, and the French Comité Economique de la Nation. The authors thank our discussants, Frederik Mishkin and Stephen Cecchetti, for valuable comments and suggestions.

(C) 2002, The Federal Reserve Bank of St. Louis. policy credibility, and in the sacrifice ratio, i.e., the cost of lowering inflation.

The debate over IT exposes a couple of odd characteristics. One is that, despite a lot of effort, empirical studies on IT have consistently failed to show convincingly that IT has been an important factor in speeding up disinflation, achieving lower inflation rates, lowering the cost of disinflation, or raising the credibility of the central bank's commitment to low inflation. An important challenge for IT supporters comes from the observation that the environment of the 1990s, when IT was first undertaken, was generally benign, implying that the particular strategy of IT may have done little to improve monetary policy outcomes over what any reasonable strategy could have achieved (Cecchetti and Ehrmann, 2000). We will review this literature in more detail in Section II.

The other oddity is that, despite the lack of empirical evidence supporting the advantages of IT, its proponents consistently argue that the failure to adopt it jeopardizes the ability of a central bank to deliver price stability. For example, Bernanke et al., after presenting pages upon pages of rather inconclusive evidence regarding the superiority of IT, nevertheless submit a plea for the Fed to adopt IT in the end, arguing that this is critical to secure price stability in the United States in the post-Greenspan era. Similarly, Alesina et al. (2001), in a discussion of the European Central Bank's (ECB) monetary policy, boldly claim that the ECB could improve its policy by adopting a version of IT, although they neither present supporting evidence for this claim nor even indicate where such evidence might be found. It is understandable that some academics find IT intellectually attractive for the outright declaration of central bank intentions and the increase in accountability implied by the announcement of an inflation target. Yet, others remain skeptical: Both the ECB (2001) and the Fed (Gramlich, 2001) have argued that they do not regard IT as an appropriate monetary policy framework.

In this paper, we contribute to the assessment of IT in several ways. After reviewing earlier studies of IT experiences, we examine the changes of shortterm interest rates and of consumer price inflation and output gaps at different frequencies, as well as show that IT has reduced short-term variability in central bank interest rates and in headline inflation. We interpret this as evidence that IT has induced central banks to pay less attention to short-run news and noise and adopt a steadier course of monetary 
policy. Next, we study central bank behavior and ask whether IT has resulted in a change in central bank reactions to key monetary policy variables. We estimate Taylor rules to describe central bank policies and find that these rules indeed indicate changes in the reaction of IT central banks to output and inflation. Furthermore, we find that this fact distinguishes them from a group of other central banks that we use as a benchmark. This difference suggests that IT has affected central bank behavior.

Third, we take an event-study approach to compare the performance of IT and non-IT central banks under two similar, exogenous shocks, namely, the oil price hikes of 1978 and 1998. We find that IT countries realized a credibility gain in the second episode compared with the first, allowing them to keep interest rates lower and face these shocks with a much less contractionary monetary policy. Our paper thus suggests that IT has indeed changed central bank behavior and that this policy yields benefits under those circumstances that central banks have historically found difficult to cope with. But comparing IT and non-IT central banks shows that the former have conformed to the standards of monetary policy set by the Bundesbank, the Fed, and the Swiss National Bank in the late 1970s and 1980s. Thus, we cannot confirm the superiority of IT over other monetary policy strategies geared at price stability.

\section{BENEFITS OF INFLATION TARGETING: WHAT ARE THEY?}

The literature on the design of monetary policy under IT and experiences with the new regimes has expanded rapidly in the past six years, partly reflecting the growing number of countries adopting such a regime. Most of the studies presented in the literature look at the time-series behavior of inflation, output, unemployment, and interest rates to see whether the new regime affected the dynamic interaction of these variables.

Early studies by Ammer and Freeman (1995) and Freeman and Willis (1995) present vector autoregression (VAR) models for real gross domestic product (GDP), price levels, and interest rates. Ammer and Freeman compare inflation forecasts generated from their VARs with actual outcomes in New Zealand, Canada, and the United Kingdom and with actual time series. They find that inflation fell by more than was predicted by the models in the early 1990 s, an indication of the effect of the new regime.
The evidence regarding the cost of disinflation is more mixed. Real GDP fell and recovered in New Zealand and the United Kingdom, but fell and remained low in Canada. Freeman and Willis (1995) note that long-term interest rates fell in the three IT countries in the early 1990s, an indication of improving monetary policy credibility. However, long-term rates came back a few years later. This occurrence could indicate that the credibility effect of IT did not last long, although Freeman and Willis ascribe most of the resurgence in long-term rates to a rise in interest rates worldwide.

Mishkin and Posen (1997) present careful accounts of the IT experiences in New Zealand, Canada, and the United Kingdom and estimate VARs of core inflation, GDP growth, and short-term central bank rates for the same countries. They point out that the disinflation had actually been almost completed in New Zealand, Canada, and the United Kingdom before the introduction of IT. This suggests that IT might have served to lock in the gains from disinflation rather than to facilitate disinflation. Mishkin and Posen then ask whether IT helped these countries to keep inflation rates down following the initial disinflation. Comparing dynamic simulations with actual outcomes, they find that inflation and interest rates remained below their counterfactuals after the introduction of IT, while output did not. In particular, actual inflation did not rise with the upswing in the business cycle, as it would have prior to IT. One shortcoming of these results is the absence of confidence bands in their dynamic forecasts, which implies that their positive conclusion relies on visual inspection alone. Laubach and Posen (1997) find further evidence supporting these results by analyzing interest rates and consumer expectations. Kahn and Parrish (1998) observe a number of inflation blips in New Zealand and Canada during the 1990s, suggesting that the central banks did not necessarily achieve better control through IT.

Debelle (1997) looks at a larger sample of IT countries, including the former three plus Sweden, Finland, Spain, and Australia. He notes the decline in inflation rates and long-term bond rates achieved in these countries but points out that unemployment increased in the same countries during the disinflation, indicating that the latter did not come without cost. Furthermore, Debelle points out that other countries achieved similar reductions in inflation rates during the first half of the 1990s, making it difficult to conclude that the disinflation is a success of the IT regime. Siklos (1999) argues that the intro- 
duction of IT should change the persistence of inflation rates, as central banks no longer tolerate lasting movements of the actual rate outside the target range. Using univariate time-series techniques and quarterly inflation data, he finds that first-order autocorrelation of inflation rates has declined significantly after the introduction of IT in Australia, Canada, and Sweden, but not so in Finland, New Zealand, Spain, and the United Kingdom. ${ }^{1}$

Other empirical studies have focused more on the behavior of central banks before and after the introduction of IT. Kahn and Parrish (1998) note that the volatility of official central bank interest rates (both nominal and real) has declined substantially after the introduction of IT. They argue that this could reflect a change in monetary policy away from activist policies, but it might also be due simply to a more stable economic environment in the 1990s. The fact that interest rate volatility decreased in the United States, too, lends some support to the second interpretation over the first. Kahn and Parrish also estimate monetary policy reaction functions for New Zealand, Canada, Sweden, and the United Kingdom relating current official rates to their own lags as well as lagged inflation, unemployment, and exchange rates. They find significant structural breaks in these functions for New Zealand and the United Kingdom. In the case of New Zealand, this break is associated with a stronger reaction of the official rate to lagged inflation and unemployment and a weaker reaction to lagged exchange rates. In the U.K. case, the break mainly reflects the loss of significance of the exchange rate in the reaction function. In neither case is it obvious that the changes in the reaction function are consistent with a shift to inflation as the primary goal of monetary policy after the adoption of IT.

Kuttner and Posen (1999) interpret the introduction of IT as a change in the central bank "type," i.e., a shift in the parameters of the central bank's preference functions, toward a stronger commitment to price stability and less discretionary policy. According to their model, such a shift should imply a decline in inflation persistence. The response of short-term interest rates to inflation shocks could increase or decrease, however, depending on the central bank type prior to IT. Kuttner and Posen estimate VARs for inflation, unemployment, and shortand long-term interest rates to test the impact of IT. Their results are rather ambiguous. For Canada and the United Kingdom, they find no change in the persistence of inflation after the introduction of IT, nor a change in the central bank reaction functions. For New Zealand, they do find a reduction in the persistence of inflation, but also a stronger reaction to unemployment with no change in the reaction to inflation in the central bank's reaction function.

Cecchetti and Ehrmann (2000) look at a sample of 23 countries, both developed and less developed, 9 of which have central banks pursuing inflation targets. A first observation from their data is that inflation rates generally came down in the 1990s compared with the 1980s independent of the geographical region of the country, their pursuit of inflation targets, or whether they were striving to enter the European Monetary Union at the end of the decade. This indicates that the 1990s were a period friendly to increased price stability. Cecchetti and Ehrmann then ask whether this improvement in price stability reflects a change in central bank aversion to inflation and whether this is particular to inflation targeters or not. They find that their measure of inflation aversion indeed rises between the mid-1980s and the 1990s among IT central banks. Unfortunately, their methodology provides no standard errors for testing whether these changes are statistically significant. A similar observation of rising inflation aversion holds for other central banks, too. Furthermore, inflation aversion of the IT central banks rises to no more than the levels of non-IT central banks. Thus, rather than being a product of the IT regime, the rise in inflation aversion may just reflect the general culture among central bankers in a decade that provided an environment conducive to price stability and, therefore, an opportunity to move away from the inflationary policies of the 1970s and 1980s.

Corbo, Landerretche Moreno, and SchmidtHebbel (2001) build on this study and show that inflation aversion increased during the 1990s among IT countries that do not belong to the group of industrialized economies, most notably Israel and Chile. Among industrialized countries, inflation targeters do not show an increase in inflation aversion. The same authors also suggest that IT central banks lowered the dynamic reactions to current inflation and output gap shocks. They also find that inflation persistence has declined substantially among IT countries since the introduction of the new regime. According to their results, inflation persistence was much higher in IT countries than in others before

\footnotetext{
1 Siklos finds that the first-order autocorrelation lost statistical significance after the introduction of IT in Finland, Spain, and the United Kingdom, but this result may be due to the relatively short sample he has in quarterly data.
} 
the introduction of IT, i.e., the new regime has produced more similar inflation dynamics.

A central feature of IT regimes is the publication of inflation forecasts and surrounding analysis to explain the central bank's assessment of monetary conditions and its monetary policy actions to the public. IT has thus contributed to improving the transparency of central bank policy. This is the focus of Chortareas, Stasavage, and Sterne (2000), who develop a measure of monetary policy transparency and use it to compare monetary policy performance across countries. These authors construct a panel data set for 87 countries and show that transparency has a significant negative impact on average inflation rates over time. This corroborates the impression that inflation targeters were able to bring and hold inflation down in the 1990s; at the same time, their results also show that IT is but one way of achieving that.

\section{INFLATION TARGETING: NEW TIME-SERIES EVIDENCE}

In this section, we present new empirical evidence on the performance of IT central banks. Following the comparative approach of previous papers, we consider a group of IT countries (viz., Australia, Canada, Chile, New Zealand, Sweden, and the United Kingdom) and a group of non-IT countries (Germany, Switzerland, and the United States). Our reference group thus contains two countries that used monetary aggregates as their intermediate targets of monetary policy in the past, Germany and Switzerland. We are primarily interested in this question: Did central bank behavior change under inflation targeting and, if so, how?

We use monthly as well as quarterly data spanning the period from September 1978 to March 2001. For Germany, we end the sample in December 1998 to account for the start of the European Monetary Union. The sample period is divided into two subperiods in order to test whether IT made any noticeable difference. The first sample runs up to June 1992, and the second sample starts in January 1993. We leave out the second half of 1992 to eliminate the interest rate effects of the crisis of the European Monetary System. The choice of subperiods is somewhat arbitrary, as some IT countries such as Chile and New Zealand had already adopted the new policy regime in 1990, whereas countries such as Sweden and the United Kingdom only started in 1993. Since we do not focus on any single country but are looking for cross-country evidence, we found this choice preferable as it allows us to use the same subperiods for all countries considered. ${ }^{2}$

\section{Volatility of Interest Rates, Inflation, and Output Gaps}

We begin this section by studying the volatility of consumer price (CPI) inflation, short-term interest rates, and output gaps. The interest rates are overnight money rates; exceptions are Chile and New Zealand where, due to data availability, we use 3month interest rates. Since output gaps calculated from GDP are not available at a monthly frequency, we generally use the index of industrial production; exceptions are Australia, New Zealand, and Switzerland, where monthly data on industrial production are not available. For Australia and New Zealand the output gap is calculated from quarterly GDP data; for Switzerland, monthly GDP data are used. The output gap is defined as the percentage difference between the actual index value and a trend derived by applying a Hodrick-Prescott (HP) filter.

Panel A of Table 1 shows average annual inflation rates together with the standard deviation of annualized monthly, annual, and biannual relative changes in the CPI for the two sample periods. These standard deviations provide a simple measure for the volatility of inflation at different frequencies. We first note the well-known fact that the level of inflation has been reduced everywhere. In the pre-IT period, the IT countries were less determined to squeeze out the inflation inherited from the 1970s and hence were troubled by much higher average inflation than the non-IT countries. Thus, the adoption of IT can be regarded as the consequence of this poor performance. With regard to the level of inflation, the new policy regime has been successful. Average inflation in IT countries has come down to the level observed for non-IT countries-Chile being an exception. Note that average inflation in the postIT sample matches the medium-run target rates for Germany (1.9 percent) and the United Kingdom (2.6 percent), while it undercuts the 2 percent target rates of Canada and Sweden by half a percentage point. Similar to average inflation, the volatility of inflation has fallen in IT as well as non-IT countries. Again, similar to average inflation, the volatility of inflation in IT countries has converged from relatively

\footnotetext{
2 The main data source is the International Financial Statistics (IFS), supplemented by data for Australia and New Zealand from the Organization for Economic Cooperation and Development (OECD).
} 


\section{Table 1}

Volatility of Inflation, Interest Rates, and Output Gaps

A. Volatility of inflation

\begin{tabular}{|c|c|c|c|c|c|c|c|c|}
\hline \multirow[t]{3}{*}{ - } & \multicolumn{4}{|c|}{ 1978:09-1992:06 } & \multicolumn{4}{|c|}{ 1993:01-2001:03 } \\
\hline & \multirow[b]{2}{*}{ Average inflation } & \multicolumn{3}{|c|}{ Standard deviation of } & \multirow[b]{2}{*}{ Average inflation } & \multicolumn{3}{|c|}{ Standard deviation of } \\
\hline & & 1 month & 12 months & 24 months & & 1 month & 12 months & 24 months \\
\hline Industrial countries & 5.9 & & 3.0 & & 2.0 & & 0.5 & \\
\hline Australia & 7.3 & & 2.8 & 2.3 & 2.5 & & 1.9 & 1.4 \\
\hline Canada & 5.9 & 4.8 & 3.1 & 1.5 & 1.5 & 3.0 & 1.1 & 0.8 \\
\hline Chile & 20.1 & 22.1 & 8.1 & 6.1 & 6.3 & 5.4 & 2.8 & 2.4 \\
\hline New Zealand & 9.8 & & 5.8 & 5.1 & 1.8 & & 1.3 & 0.9 \\
\hline Sweden & 7.5 & 7.9 & 3.1 & 2.7 & 1.5 & 4.2 & 1.1 & 0.8 \\
\hline UK & 7.4 & 8.0 & 4.4 & 3.8 & 2.6 & 4.5 & 0.7 & 0.4 \\
\hline Germany & 3.1 & 4.1 & 2.0 & 1.9 & 1.9 & 2.8 & 0.6 & 0.5 \\
\hline Switzerland & 3.7 & 6.8 & 1.9 & 1.8 & 1.1 & 3.3 & 0.6 & 0.5 \\
\hline US & 5.5 & 4.3 & 3.4 & 3.0 & 2.6 & 2.2 & 0.6 & 0.5 \\
\hline
\end{tabular}

\section{B. Volatility of interest rates}

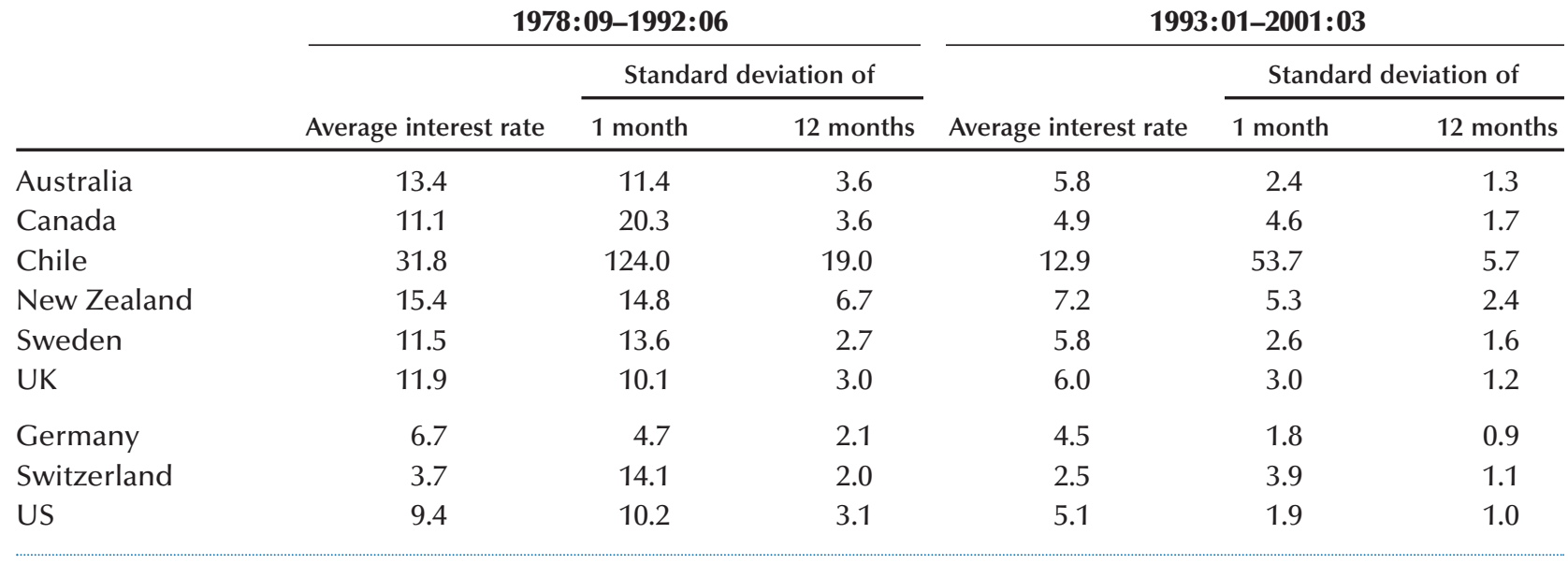

\section{Volatility of output gaps}

\begin{tabular}{|c|c|c|c|c|}
\hline & \multicolumn{2}{|c|}{ 1978:09-1992:06 } & \multicolumn{2}{|c|}{ 1993:01-2001:03 } \\
\hline & \multicolumn{2}{|c|}{ Standard deviation of } & \multicolumn{2}{|c|}{ Standard deviation of } \\
\hline & 3 months & 12 months & 3 months & 12 months \\
\hline Australia & 4.7 & 2.4 & 2.7 & 1.2 \\
\hline Canada & 9.0 & 4.7 & 4.7 & 2.1 \\
\hline Chile & 43.1 & 9.5 & 34.5 & 7.3 \\
\hline New Zealand & 14.7 & 4.5 & 4.1 & 1.9 \\
\hline Sweden & 10.3 & 3.3 & 11.2 & 3.4 \\
\hline UK & 7.7 & 3.2 & 3.2 & 1.2 \\
\hline Germany & 7.3 & 2.4 & 6.9 & 3.0 \\
\hline Switzerland & 2.0 & 1.6 & 1.2 & 0.9 \\
\hline US & 6.0 & 3.3 & 3.2 & 1.4 \\
\hline
\end{tabular}

NOTE: Entries are in percent. For New Zealand, the sample starts in 1982:03; for Germany, it ends in 1998:12; for Switzerland, it starts in 1980:01. 


\section{Table 2}

\section{Monthly Taylor Rules}

\begin{tabular}{|c|c|c|c|c|c|c|c|}
\hline & Constant & $\operatorname{Gap}_{t-1}$ & $\pi_{t-1}$ & $i_{t-1}$ & $\mathbf{R}^{2}$ & STD & $\begin{array}{c}\text { Long-run response } \\
\text { to inflation }\end{array}$ \\
\hline \multicolumn{8}{|c|}{ A. 1978:09-1992:06 } \\
\hline Canada & $1.99 * *$ & $0.16^{* *}$ & $0.24^{* *}$ & $0.62^{* *}$ & 0.78 & 1.77 & 0.75 \\
\hline Chile & $7.19 * *$ & 0.05 & -0.01 & $0.77^{* *}$ & 0.60 & 9.68 & \\
\hline Sweden & $1.49 * *$ & 0.01 & $0.07^{*}$ & $0.82^{* *}$ & 0.78 & 1.07 & 0.41 \\
\hline UK & $1.47^{* *}$ & 0.05 & $0.08^{* *}$ & $0.83^{* *}$ & 0.89 & 0.79 & 0.45 \\
\hline Germany & $0.26^{* *}$ & $0.04^{*}$ & $0.06^{*}$ & $0.94^{* *}$ & 0.97 & 0.38 & 0.96 \\
\hline Switzerland & 0.00 & -0.01 & $0.08^{*}$ & $0.92^{* *}$ & 0.81 & 1.15 & 0.99 \\
\hline US & $0.45^{*}$ & 0.05 & $0.08^{*}$ & $0.90^{* *}$ & 0.93 & 0.90 & 0.77 \\
\hline \multicolumn{8}{|c|}{ B. 1993:01-2001:03 } \\
\hline Canada & $0.64^{* *}$ & $0.10^{* *}$ & $-0.12^{*}$ & $0.90^{* *}$ & 0.91 & 0.44 & \\
\hline Chile & $3.41^{* *}$ & 0.04 & $0.50^{* *}$ & $0.45^{* *}$ & 0.44 & 3.79 & 0.90 \\
\hline Sweden & $0.22 *$ & $0.03 * *$ & $0.08^{* *}$ & $0.93^{* *}$ & 0.99 & 0.23 & 1.10 \\
\hline UK & $0.47^{*}$ & 0.03 & $0.10^{*}$ & $0.88^{* *}$ & 0.89 & 0.24 & 0.81 \\
\hline Germany & $0.11^{*}$ & $0.02^{*}$ & $0.09 *$ & $0.92^{* *}$ & 0.99 & 0.12 & 1.12 \\
\hline Switzerland & $0.12^{*}$ & -0.00 & 0.06 & $0.91^{* *}$ & 0.95 & 0.31 & 0.66 \\
\hline US & $0.34^{* *}$ & $0.09 * *$ & -0.10 & $0.94^{* *}$ & 0.98 & 0.14 & \\
\hline
\end{tabular}

NOTE: Gap is the output gap, $\pi$ the annual rate of inflation, $i$ the nominal interest rate, $R^{2}$ the adjusted R-squared value, STD the standard deviation of the residuals. For Germany, the sample ends in 1998:12; for Switzerland, it ends in 2000:09. * and ** indicate significance at the 5 and 1 percent confidence levels, respectively.

high levels to the levels observed in the non-IT countries of the reference group. This result suggests that the IT countries have joined our non-IT group in their determination to stabilize inflation over the medium run and to gain credibility in this way. But note that, with the exception of the United Kingdom, the volatility of inflation at the 12- and 24-month frequencies still remains above the level observed for our reference group of non-IT countries.

Panel B of Table 1 provides similar information for short-term interest rates. Given the improved inflation performance in all countries, it is no surprise that between the sample periods the average levels of interest rates have fallen. The table shows that the volatility of short-term interest rates has decreased, too. Similar to what one observes for the volatility of inflation, the volatility of overnight rates in IT countries converges to the lower level observed in our non-IT countries, though it remains higher for IT than for non-IT countries in the post-IT period. The United Kingdom again is the exception.
Finally, consider panel C of Table 1, which shows the volatility of the output gaps. They, too, have fallen generally between the sample periods in all countries. Notable exceptions are Germany and Sweden, where the volatility at the 12-month frequency has increased in the post-IT sample.

\section{Taylor Rules}

The inspection of the data suggests that the behavior of central banks has changed between the sample periods. To study this in more detail, we estimate dynamic Taylor rules by combining the Taylor equation with the assumption of interest-rate smoothing. We do this for both monthly and quarterly data. Overnight money market rates serve as the dependent variable. The explanatory variables are the inflation rate and the output gap, apart from the lagged overnight rate.

Evidence from Monthly Taylor Rules. A first set of estimates uses monthly data. Based on a 
specification search relying on the Akaike information criterion (AIC), we include both inflation and the output gap with one lag in all equations. Table 2 has the results for the two sample periods. The first thing to note is that the standard deviations of the residuals (or standard errors) are considerably lower in the post-IT period for all countries. A standard likelihood-ratio test indicates that the differences are statistically significant.

The table shows that, judged by $R^{2}$ values, the estimated Taylor rules fit the data well for all countries except Chile. This result holds for both groups of countries and confirms findings reported in earlier literature. The estimated coefficients generally have the correct signs. Exceptions are the Swiss response to output in both sample periods, the Chilean response to inflation in the pre-IT period, and the United States and the Canadian responses to inflation in the post-IT period. Only in the Canadian case, however, is the coefficient significantly different from zero. Overall, the Taylor rules appear to be reasonable descriptions of central bank behavior. Table 2 shows the long-run responses of the interest rates to inflation together with the estimated coefficients.

According to this table, Canada is the only country in the IT group where the interest rate responded significantly to the output gap in the first sample period. Reactions to the output gap are not significantly different from zero in the other three countries. The reaction to lagged inflation was significantly positive in Canada, Sweden, and the United Kingdom during that period, and not significantly different from zero in Chile. The short-run reaction to inflation was more than three times larger in Canada than in Sweden and the United Kingdom. The greater persistence of the interest rate in the latter two countries, however, implied that the differences in the long-run responses are less pronounced.

These patterns have changed somewhat in the post-IT period. Sweden and Canada now show significant reactions to the output gap. The estimates for the United Kingdom, Sweden, and Chile indicate significant, positive reactions to lagged inflation, while the estimate for Canada shows a negative sign. Compared with the first period, the long-run responses to inflation almost doubled for the United Kingdom and more than doubled for Sweden. Chile's long-run reaction to inflation is now similar to that of the United Kingdom and Sweden. The persistence in interest rates increased somewhat in the United Kingdom, Sweden, and Canada, but dropped in
Chile. Overall, the substantial increase in the longrun response to inflation is the strongest indicator of a change in central bank behavior that we take from these estimates.

Consider, then, the non-IT countries. In the first subsample, the estimate for Germany shows positive and significant reactions of the overnight rate to both the output gap and inflation. For neither Switzerland nor the United States do we find a significant reaction of short-term rates to the output gap, but their reactions to lagged inflation are in line with Germany's. The results remain similar for Germany and Switzerland in the post-IT sample, although the Swiss reaction to inflation loses statistical significance. The U.S. reaction to inflation even changes sign and loses significance, while its reaction to the output gap is larger and significant.

Comparing IT and non-IT countries in the pre-IT sample, we see the starkest differences in their longrun reactions to inflation, which are uniformly much lower among the countries that later adopted IT than in Germany and Switzerland. This changed in the post-IT period, as the long-run reactions to inflation have increased by more in IT countries than in Germany. The suggestive result then is that the move to IT marks a convergence in central bank behavior of the first group to the Bundesbank and the Swiss National Bank, the two banks that showed the strongest determination to keep inflation down in the 1970s and 1980s. This finding corroborates the results reported by Cecchetti and Ehrmann (2000) and Corbo, Landerretche Moreno, and Schmidt-Hebbel discussed above. Finally, the estimates support the conjecture that under the IT regime central banks give less weight to stabilizing the business cycle. With the exception of Sweden, the reaction of IT countries to the output gap is lower in the post-IT period than before, though still stronger than in Germany.

We pursue this analysis further by embedding our Taylor rules into three-dimensional VARs for short-term inflation, the output gap, and the interest rate. All estimates employ a constant and only one lag. Based on the Cholesky decomposition, we can use the VARs to study the impulse responses of the overnight rates. Figure 1 shows results for the United Kingdom and Germany. For both countries and both sample periods we observe significantly positive responses of central bank interest rates to innovations in inflation and output gaps. This replicates the information from our estimates of Taylor rules. Beyond that qualitative result, Figure 1, in panels A 


\section{Figure 1}

\section{Response of the Overnight Rate}

\section{A. United Kingdom, 1978-92}
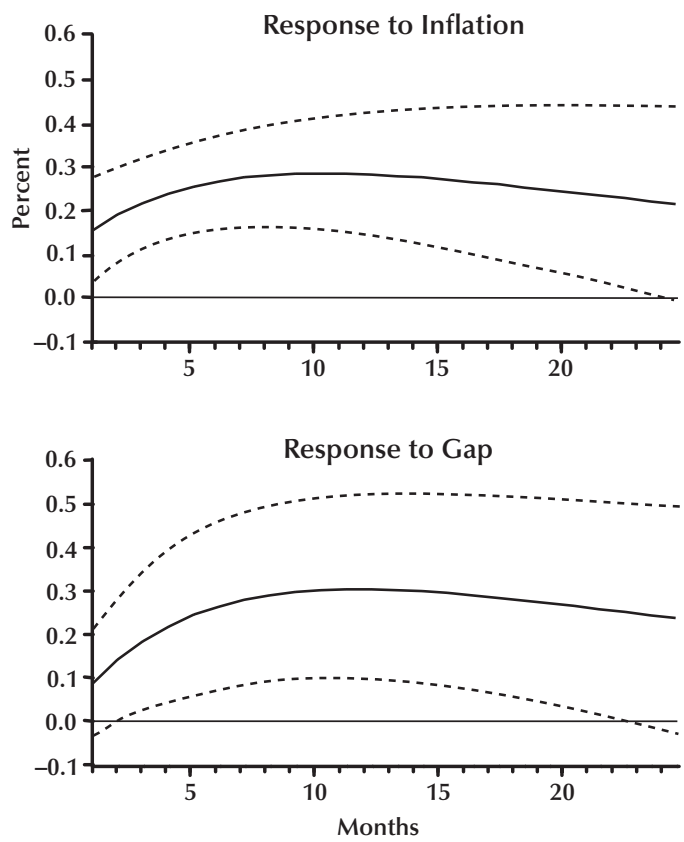

\section{Germany, 1978-92}
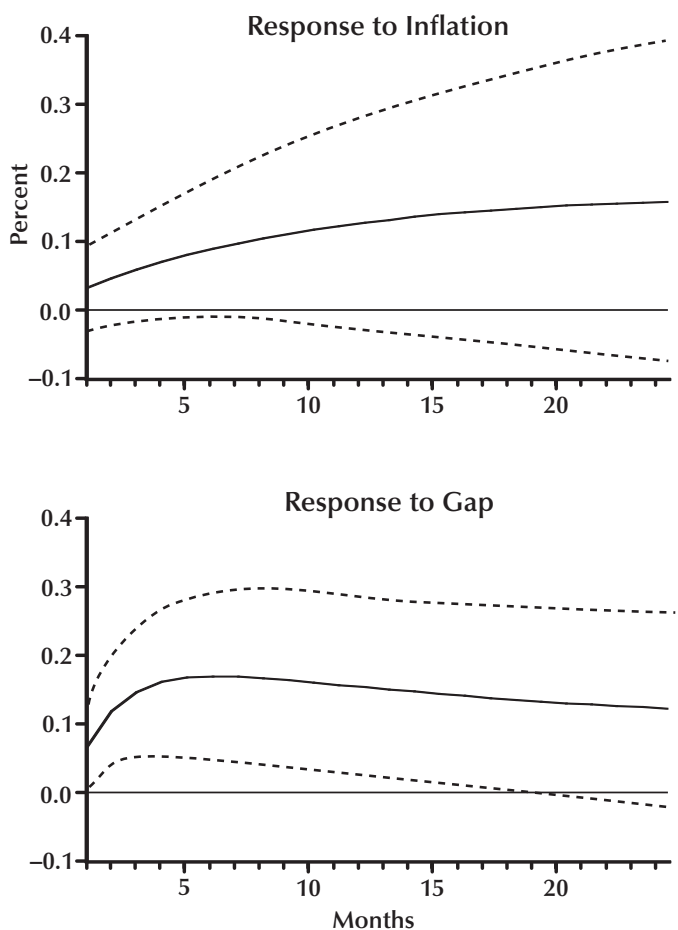

\section{B. United Kingdom, 1993-01}
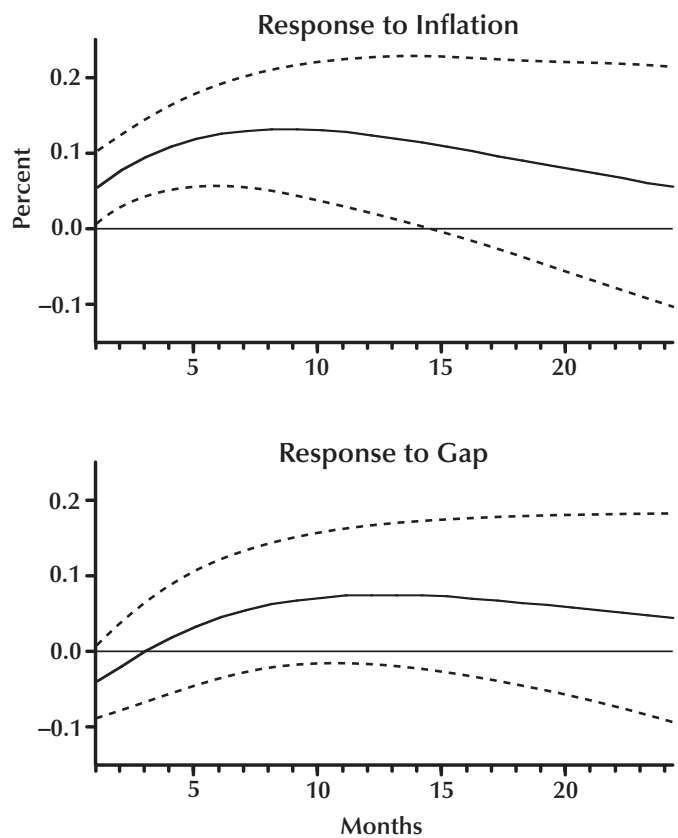

\section{Germany, 1993-98}
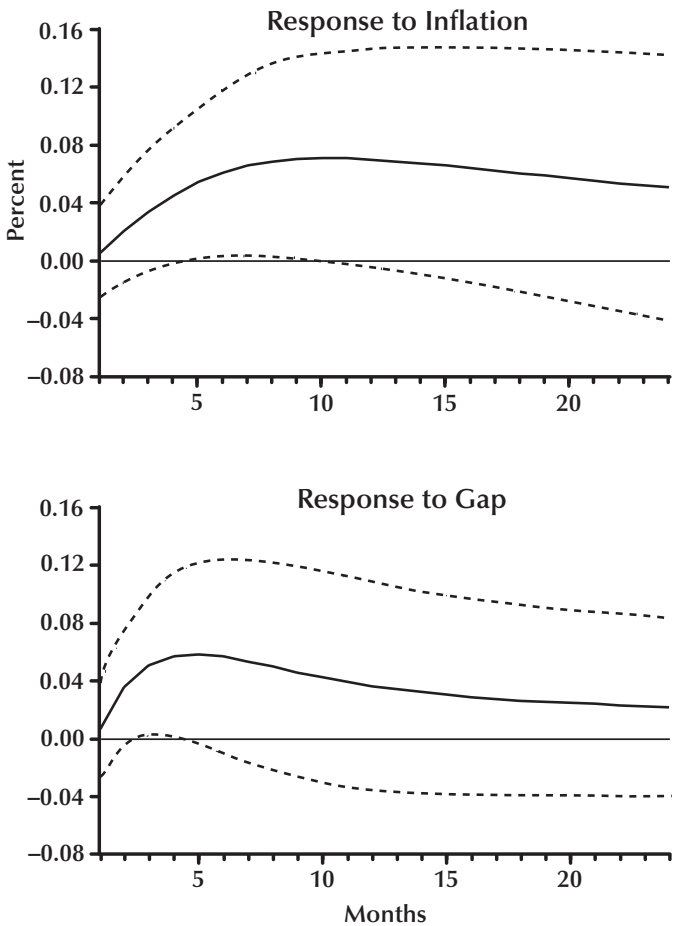

NOTE: Responses were calculated to Cholesky one standard deviation innovations \pm standard errors. 


\section{Figure 2}

\section{Contribution of Inflation Shocks to the Overnight Rate Variance}

\section{A. United Kingdom}

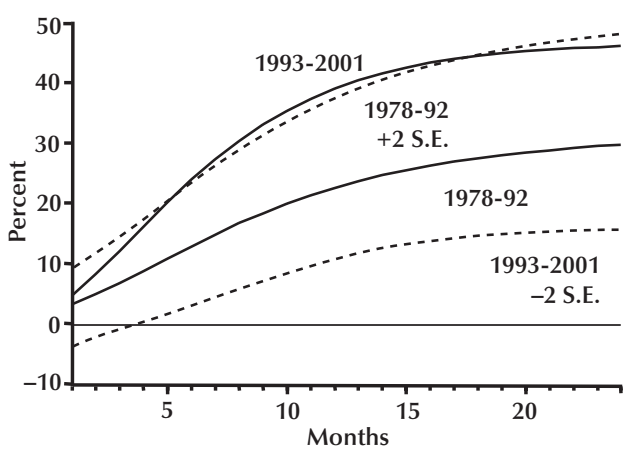

\section{Germany}

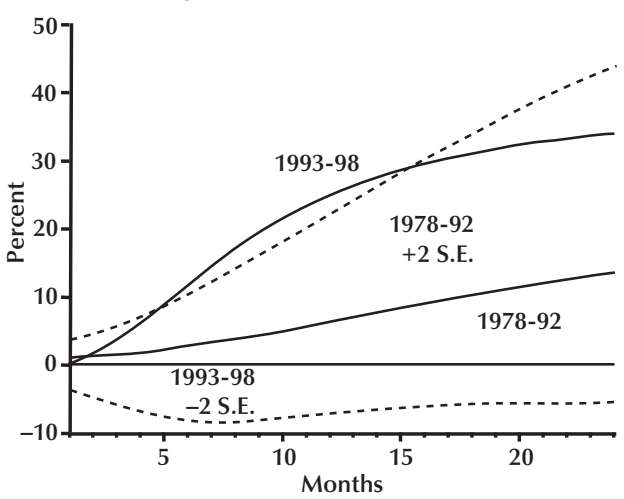

\section{B. Sweden}

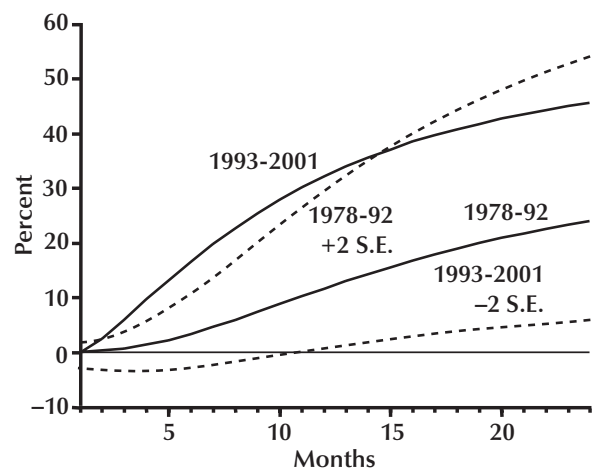

\section{Switzerland}

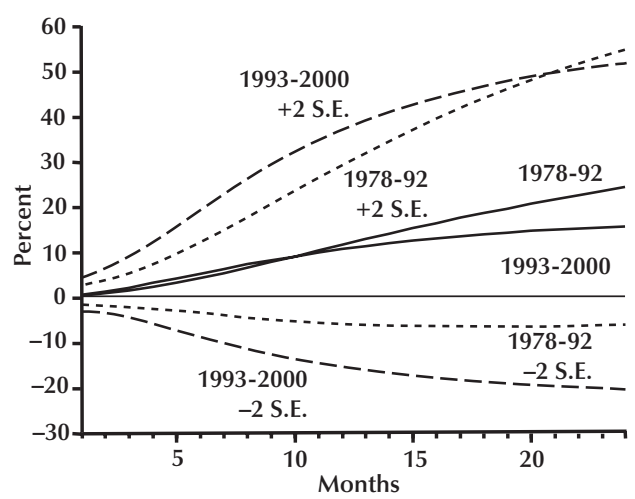

and B, shows for the United Kingdom that the post-IT impulse response to a one-standard-deviation shock to the inflation rate is considerably smaller in magnitude than the pre-IT impulse response. The former never exceeds 0.12 , while the latter goes above 0.2 after six months. Thus, while the long-run response to inflation has increased strongly (as shown in Table 2), the impulse response functions suggest that the short-run response to inflation shocks has become less aggressive. The impulse response functions for Germany (Figure 1, C and D) convey the same impression. In the post-IT sample, the impulse response never exceeds 0.08 , but it does climb above 0.1 in the pre-IT sample. Also, these two panels in the figure show similar reductions in the impulse responses to output-gap shocks. Thus, the estimates suggest that both IT and non-IT central banks moved to a less activist monetary policy in the 1990s.

Consider next the contributions that the inno- vations in the inflation rate at various lags made to the variance of the overnight rates. This is an indicator of the degree to which monetary policy actions were directed at counteracting inflation shocks. The question is whether the relative importance of these shocks to interest rate policy has risen in the post-IT period. Figure 2 shows the results for two IT countries, the United Kingdom and Sweden, and for two non-IT countries, Germany and Switzerland. We cannot apply this comparison to Canada, Chile, and the United States because the monthly VAR estimates for these countries suggest a counterintuitive, negative response of the overnight rate to inflation in at least one of the sample periods.

Each of the panels in Figure 2 provides the percentage of the variance of the interest rate due to innovations in the inflation rate for both sample periods. For the United Kingdom, Figure 2A shows a strong increase in the relative importance of 
inflation shocks as a source of interest rate variance in the post-IT period. At lag 12, their contribution to the variance of the overnight rate reaches 40 percent, compared with less than 25 percent in the pre-IT period. Note that the 1993-2001 line lies outside the confidence interval around the 1978-92 line for lags 5 to 18 . The picture thus suggests that U.K. monetary policy has become more strongly determined to fight inflation under the IT regime. Similar findings emerge from Figure 2B for Sweden. At the annual lag, the contribution of inflation shocks to the variance of the Swedish money market rate rose from 10 percent in the pre-IT period to 35 percent in the post-IT period. It is noteworthy that a similar result holds for Germany. There, too, the contribution of inflation shocks to the variance of the overnight rate was higher in the post-IT period. Figure $2 \mathrm{C}$ shows that, at lag 12 , inflation shocks contributed less than 10 percent to the variance of Germany's money market rate before 1992 , but 25 percent thereafter. Again, the data convey the impression of a convergence in central bank behavior that coincides with the introduction of inflation targeting in the IT countries. An exception is Switzerland, where the estimated contribution of inflation shocks to the variance of money market rates appears to have been quite small in both periods. But note that the underlying estimate for the post-IT period is poor, which might reflect the fact that Swiss monetary policy to a larger extent is directed at controlling the exchange rate.

Evidence from Quarterly Taylor Rules. We now turn to quarterly estimates of Taylor rules, which allow us to consider a broader group of countries. Thus, we can include Australia and New Zealand as two additional inflation targeters. For these countries the output gap is estimated from real GDP and an HP filter. Inflation continues to be measured in terms of the CPI. Switching from a higher to a lower frequency may change the dynamics of the Taylor estimate. Using the AIC again, we find that the contemporaneous output gap and the contemporaneous inflation rate fit better than the first lags in most Taylor models. Exceptions are Canada and Switzerland in the first sample and Canada, Sweden, Germany, and Switzerland in the second sample. In these cases, the first lag of the output gap gave better estimation results. Table 3 provides the results.

As before, the estimates look reasonable and fit the data well, with the exception of Chile and Switzerland. If we disregard the latter, all signs are as expected except the output gap response of the
United Kingdom in the post-IT sample, as well as the Canadian inflation response in that period; but these coefficients are not statistically different from zero. Note that the quarterly estimates provide a significant positive reaction to inflation for the United States in the post-IT sample, in contrast to the estimate based on monthly data.

As in the case of monthly Taylor rules, the quarterly estimates suggest that the behavior of central banks has changed between the sample periods. Among the inflation targeters, Canada is the only country where the output response of interest rates increased between the first and the second sample. A similar observation for Sweden (made from monthly data) has vanished. Among the non-IT countries, it is again in the United States where the reaction to the output gap is stronger in the second sample period. The short-run reaction to inflation is larger in the second period for the IT countries except Canada and New Zealand. More importantly, the long-run response to inflation increases for all IT countries. In the United Kingdom, Sweden, and Australia, it is more than twice as large as in the first sample period. These changes in long-run inflation responses are in line with the estimates from monthly Taylor rules for the United Kingdom, Sweden, and Chile. Turning to the non-IT countries, we find that the long-run response to inflation goes up in Germany and decreases slightly in the United States. Overall, the estimates from quarterly data confirm the impression from monthly data: The adoption of IT has produced a convergence of central bank behavior to that of the Bundesbank in the 1980s and 1990s.

A notable feature of our estimates is that the estimated long-run response of short-term interest rates to inflation is below unity in all cases except for Germany, Sweden, and the United Kingdom in the post-IT period. This contrasts with the familiar claim of the literature on Taylor rules that the response of interest rate policy to inflation should exceed unity in order to guarantee that monetary policy is able to stabilize inflation. The fact that we do not find this for most countries, including the United States, is puzzling.

One reason for this finding may be that earlier studies have commonly used GDP deflators instead of CPIs for computing the rate of inflation. In the appendix, we show that the long-run response coefficient of the federal funds rate to U.S. inflation is about 1.5 if the GDP deflator is used but 1.0 or less if the GDP deflator is replaced by the CPI. From a 


\section{Table 3}

\section{Quarterly Taylor Rules}

\begin{tabular}{|c|c|c|c|c|c|c|c|c|}
\hline & Constant & $\operatorname{Gap}_{t}$ & $\operatorname{Gap}_{t-1}$ & $\pi_{t-1}$ & $i_{t-1}$ & $\mathbf{R}^{2}$ & STD & $\begin{array}{c}\text { Long-run response } \\
\text { to inflation }\end{array}$ \\
\hline \multicolumn{9}{|c|}{ A. 1978:Q3-1992:Q2 } \\
\hline Australia & $-25.4^{*}$ & $0.27^{*}$ & & 0.03 & $0.84^{* *}$ & 0.78 & 1.39 & 0.21 \\
\hline Canada & $2.97^{* *}$ & & $0.16^{* *}$ & $0.38^{* *}$ & $0.52^{* *}$ & 0.68 & 1.68 & 0.78 \\
\hline Chile & $9.06^{* *}$ & 0.23 & & 0.26 & $0.54^{* *}$ & 0.32 & 11.48 & 0.57 \\
\hline New Zealand & -17.85 & $0.22^{*}$ & & $0.35^{* *}$ & $0.56^{* *}$ & 0.86 & 1.64 & 0.79 \\
\hline Sweden & $1.81^{*}$ & $0.13^{*}$ & & 0.11 & $0.76^{* *}$ & 0.72 & 1.50 & 0.49 \\
\hline UK & $3.22^{* *}$ & 0.09 & & $0.22^{* *}$ & $0.59 * *$ & 0.79 & 1.06 & 0.54 \\
\hline Germany & $0.75^{* *}$ & $0.16^{* *}$ & & $0.18^{*}$ & $0.81^{* *}$ & 0.95 & 0.53 & 0.91 \\
\hline Switzerland & 0.27 & & -0.03 & 0.01 & $0.96^{* *}$ & 0.85 & 0.94 & 0.35 \\
\hline US & 0.74 & $0.15^{*}$ & & $0.16^{*}$ & $0.81^{* *}$ & 0.85 & 1.20 & 0.87 \\
\hline \multicolumn{9}{|c|}{ B. 1993:Q1-2001:Q1 } \\
\hline Australia & $-19.8^{*}$ & $0.21^{*}$ & & 0.08 & $0.85^{* *}$ & 0.89 & 0.33 & 0.55 \\
\hline Canada & $1.99 * *$ & & $0.26^{* *}$ & -0.20 & $0.64^{* *}$ & 0.69 & 0.59 & \\
\hline Chile & $6.33^{* *}$ & 0.03 & & $0.96^{* *}$ & & 0.41 & 3.18 & 0.96 \\
\hline New Zealand & $1.68^{*}$ & 0.10 & & 0.28 & $0.68^{* *}$ & 0.70 & 0.83 & 0.88 \\
\hline Sweden & $0.84^{* *}$ & & $0.10^{* *}$ & $0.35^{* *}$ & $0.74^{* *}$ & 0.95 & 0.45 & 1.32 \\
\hline UK & $1.71^{* *}$ & -0.11 & & $0.59^{* *}$ & $0.46^{* *}$ & 0.81 & 0.30 & 1.09 \\
\hline Germany & $0.22^{*}$ & & $0.07^{* *}$ & $0.22 *$ & $0.83^{* *}$ & 0.99 & 0.16 & 1.28 \\
\hline Switzerland & $0.30^{*}$ & & $0.27^{* *}$ & 0.09 & $0.84^{* *}$ & 0.94 & 0.31 & 0.58 \\
\hline US & $0.78^{* *}$ & $0.28^{* *}$ & & $0.18^{*}$ & $0.76^{* *}$ & 0.95 & 0.21 & 0.74 \\
\hline
\end{tabular}

NOTE: Gap is the output gap, $\pi$ the annual rate of inflation, $i$ the nominal interest rate, $R^{2}$ the adjusted R-squared value, STD the standard deviation of the residuals. For Germany, the sample ends in 1998:Q4; for Switzerland, it ends in 1980:Q1. * and ** indicate significance at the 5 and 1 percent confidence levels, respectively.

purely statistical point of view, the difference can be traced to the markedly higher variance of the CPI. But the question remains: Which price index is the more appropriate one? If central banks, in practice, care more about inflation derived from CPIs than from GDP deflators, our estimates suggest that central bank interest rates do not respond sufficiently to inflation in most countries even in the post-IT period.

To check the contribution of inflation shocks to the variance of interest rates, we again estimate three-dimensional VARs for the inflation rate, the output gap, and the interest rate. All estimates employ a constant and only one lag. Note that the quarterly Taylor estimates show contemporaneous reactions to inflation for all countries and to the output gap for some countries. This implies that the interest rate equations of the VARs differ from the estimated Taylor equations. In Figure 3, we plot the contribution of inflation shocks to the variance of money market rates for all countries, except Canada, Chile, and Switzerland, and for both sample periods. For the United Kingdom, Sweden, and Germany, the estimates with quarterly data replicate the results from monthly data (see Figure 2, A through C). For the other countries, the results are more mixed. In the cases of New Zealand and the United States, we find a smaller contribution of inflation shocks to the variance of money market rates in the post-IT period. For Australia, finally, the contribution of the inflation shocks increases, but only slightly so. In sum, we find that the quarterly data support the 


\section{Figure 3}

\section{Contribution of Inflation Shocks}

\section{A. United Kingdom: Contribution to} Overnight Rate Variance

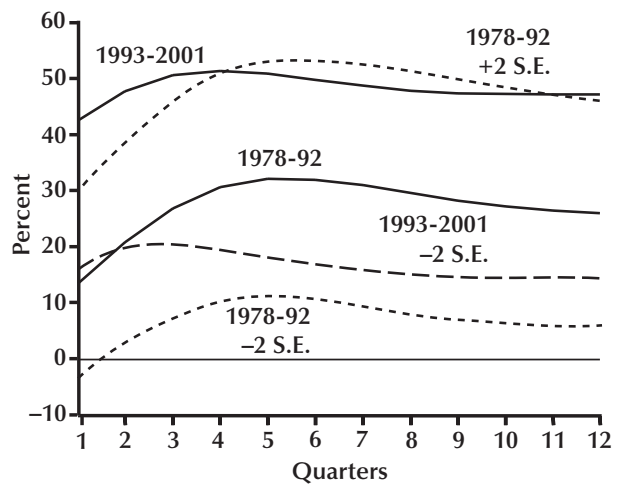

\section{New Zealand: Contribution to} Variance of 3-Month Bank Bill Rate

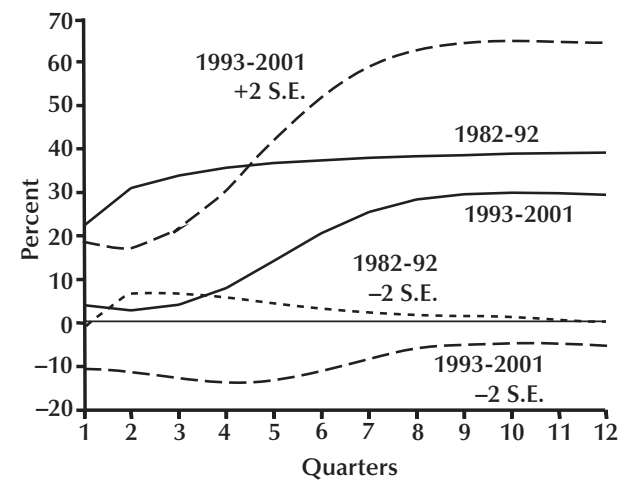

E. Australia: Contribution to Overnight Rate Variance

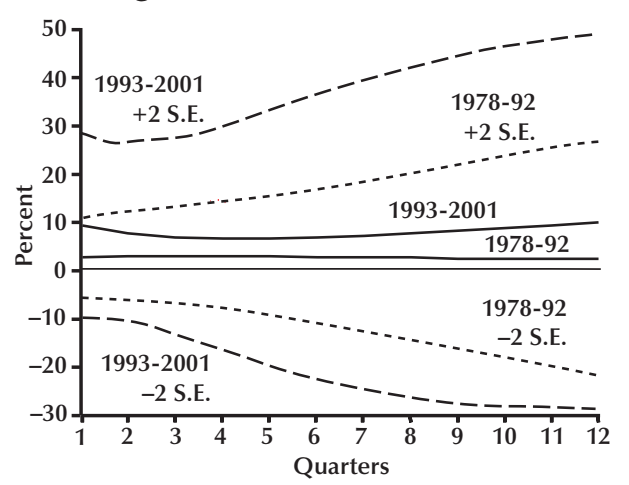

B. Sweden: Contribution to Overnight Rate Variance

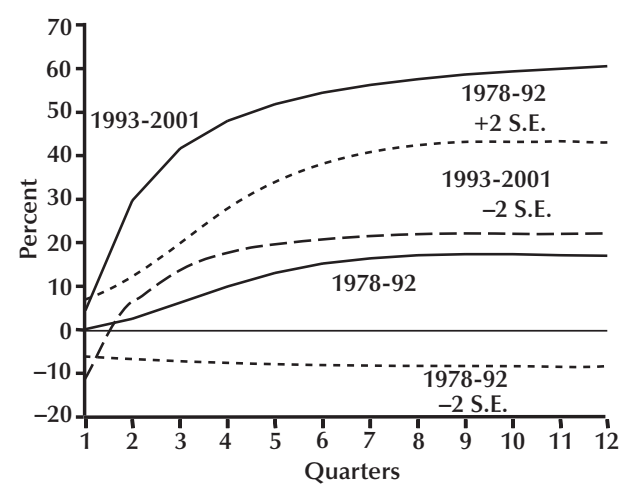

D. Germany: Contribution to Overnight Rate Variance

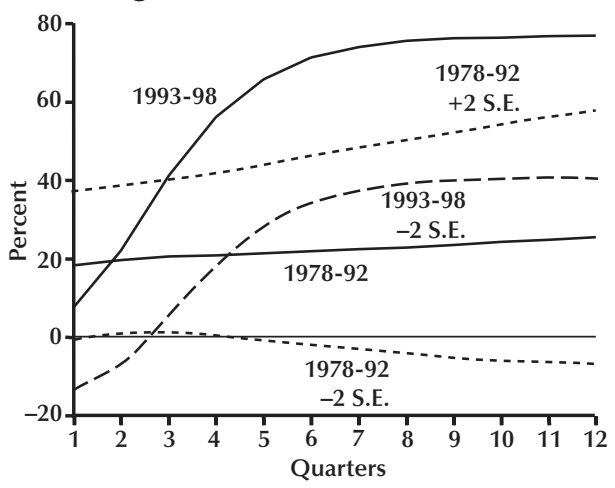

F. United States: Contribution to Variance of Federal Funds Rate

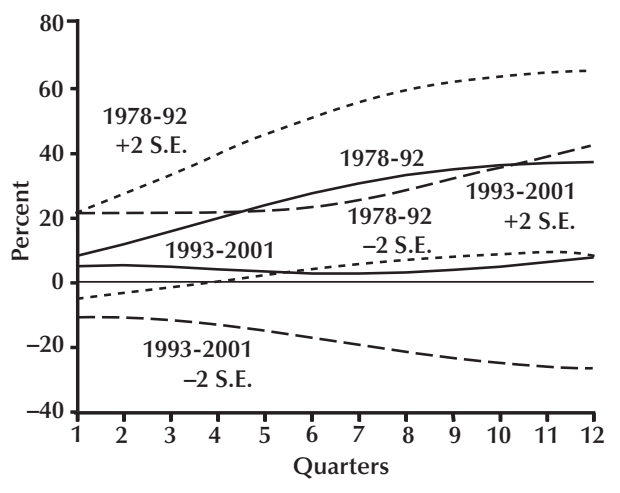


results derived from monthly data for the IT countries Sweden and the United Kingdom and for the non-IT country Germany, while the results for the other countries remain mixed.

\section{INFLATION TARGETING: AN EVENT STUDY}

An important shortcoming of the analysis presented in the previous section and of similar work in the literature is the assumption that the economic environment of monetary policy remains basically unchanged in the period under consideration. In particular, it is a maintained, though usually only implicit, hypothesis that monetary policy was exposed to the same type of shocks in different periods, so that any observed changes in central bank performance or in the level and dynamics of interest rates and inflation rates can be attributed to changes in the monetary regime. Regression analysis of central bank reaction functions or inflation dynamics of course allow for exogenous shocks of different magnitude in different periods of time. Nevertheless, the analysis necessarily assumes that all exogenous shocks are drawn from the same distribution and that monetary policymakers interpreted their environment in this way. This is obviously a very strong assumption and one that is hard to verify. But if we cannot be sure that monetary policy responses as described by empirical reaction functions are truly reactions to shocks from the same distribution, the analysis loses much of its strength.

In this section, we look at the issue in a different way. We do not ask how the average response of central banks to many shocks, as described by regression analysis, changed before and after the adoption of IT. Rather, we compare central bank performance and monetary policy outcomes in two historical episodes in which monetary policy was faced with very similar, exogenous shocks. By ensuring that the nature and the size of the shock are truly similar, we can be more confident that we compare monetary policy under truly comparable circumstances, yet with one important difference, namely, the adoption of IT by some central banks in one of the episodes considered.

The kind of experiment we pursue here demands that the shocks we look at be truly exogenous to monetary policy in the countries considered; that is, we should look at shocks originating outside these countries. With this in mind, we choose two periods of rising crude oil prices. From the point of view of the central banks in our analysis, episodes of rising oil prices present the dilemma of a negative supply shock. Rising oil prices lead to a slowdown of economic growth and rising inflation. Monetary policy can attempt to hold unemployment down, but only at the cost of even higher inflation rates. This is the experience of the "stagflations" most industrialized countries first encountered following the oil price shock of 1973 . While markets may not have fully understood the macroeconomic consequences of rising crude oil prices immediately after the first oil price shock, it is plausible to assume that they did subsequently.

The two episodes we look at are the periods of rising crude oil prices starting in July 1978 and in December 1998. During the first episode, the price per barrel of crude oil increased from $\$ 13.15$ to $\$ 39.57$ (U.S.), a total increase of 201 percent. The peak was reached in November 1979. During the second episode, the price increased from $\$ 10.41$ per barrel to $\$ 29.62$, for a total of 185 percent reached in June 2000 . After a temporary drop to $\$ 27.93$ per barrel in July 2000, the oil price rose again to $\$ 32.68$ in September. The price hikes are thus similar in magnitude, although oil prices rose faster initially in the second episode. Figure 4A illustrates the similarity of the price developments in the two periods.

We are interested in exploring the differences in the monetary policy responses to these two oil price hikes. This would be much easier if we could safely assume that the economies we look at are the same in terms of aggregate demand and supply performance in both episodes. However, the oil price hikes of the 1970s induced important substitutions away from the use of oil as a source of energy in the industrialized world. In many countries, tax policies have amplified these substitution processes. This is indicated by the concept of "energy intensity," which relates annual energy consumption to annual economic activity. According to the OECD (2001), energy intensity of European industries improved by an average 1.5 percent annually in the European Union countries during the 1990s, driven by gains made particularly in Germany and Sweden. Energy intensity improved by an annual average rate of 1.9 percent in the North American Free Trade Agreement (NAFTA) region during the 1980s; it was flat in 1990-93, but improved again thereafter. These gains were realized mainly by the United States and Canada. The improvements in energy intensity suggest that the economies became less vulnerable to oil price shocks, and the inflationary consequences of the second episode we consider should be less dramatic as a result. However, the data also suggest 


\section{Figure 4}

\section{Oil Prices}

\section{A. Two Oil Price Hikes}

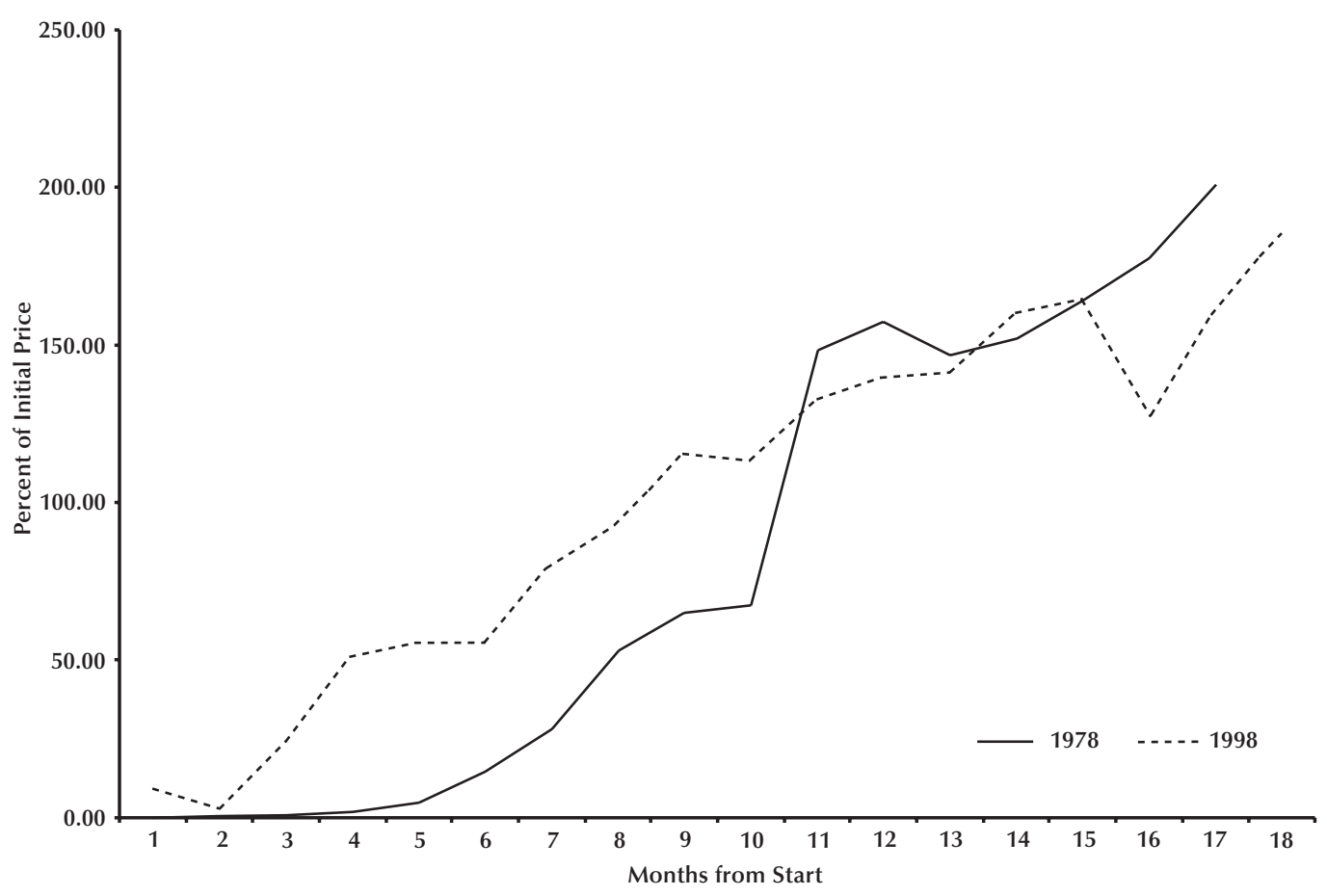

\section{B. First Oil Price Shock: Inflation}

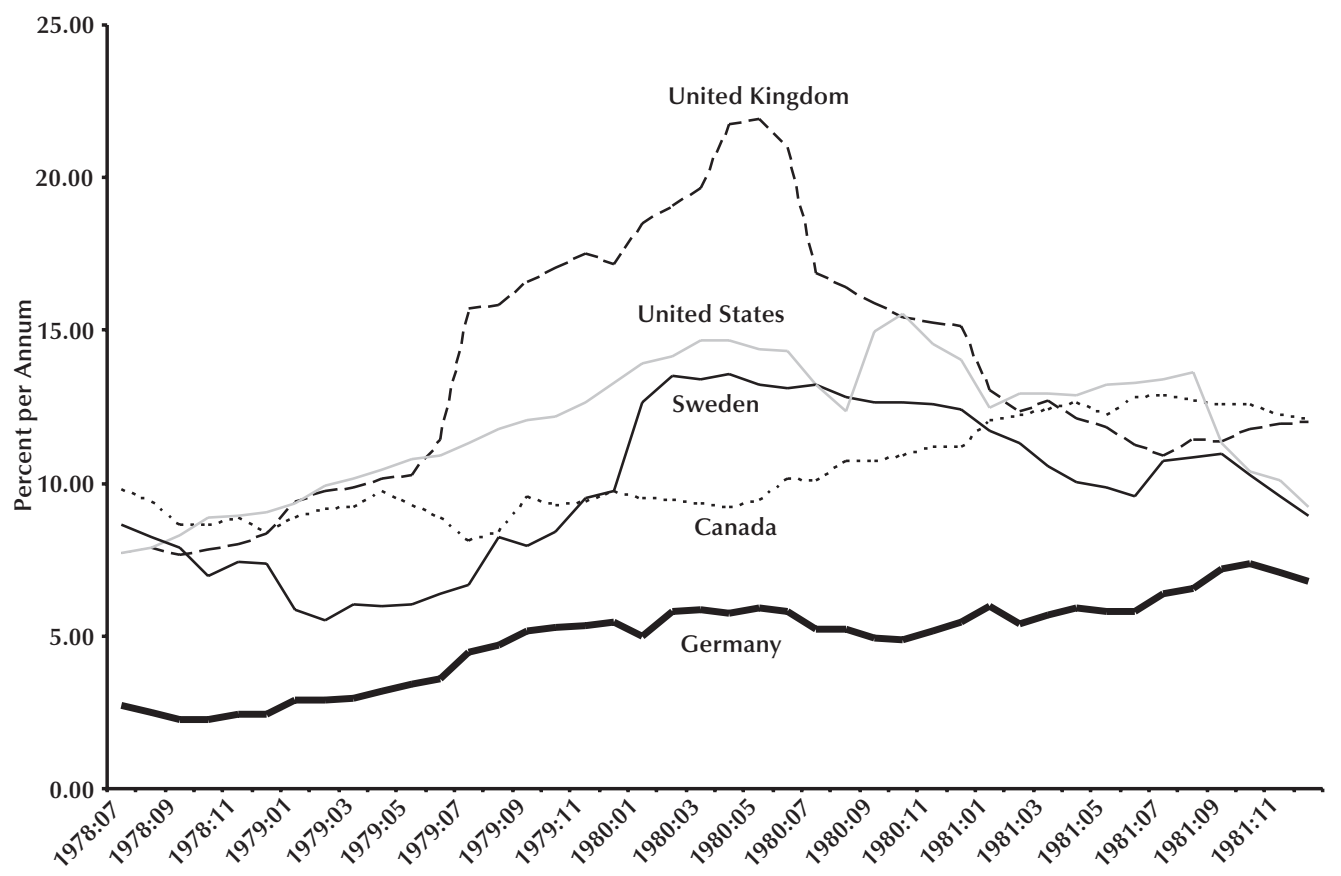


that improvements in energy intensity are not special to IT or non-IT countries. Therefore, using non-IT countries as a benchmark, we can control for the effects of these substitution processes.

\section{The Method of Double Differences}

We wish to evaluate the effect of a change in monetary regime, the adoption of IT, on a number of monetary indicators of a country. The main problem with such an assessment is that the monetary policy regime may not be the only relevant variable that changed between the two periods we compare. A change in energy intensity is just one example of other relevant developments that might have occurred. A widespread change in public perceptions about the role and the goals of monetary policy is another example.

A standard method for dealing with this kind of evaluation in a public policy context is the "method of double differences." Consider a variable of interest, $y$, and assume that this variable is a function of an exogenous variable, $x$, and a vector of other, exogenous variables, $Z$, as well as a policy regime. We are interested in how the response of $y$ to a change in the exogenous variable $x$ is affected by a change in the policy regime. We have observations of $y$ for a group of countries $i=1, \ldots, N$ that underwent a regime change and a group of countries $j=1, \ldots, M$ where no regime shift occurred. In both groups of countries, the indicator is affected by the same exogenous variables, and we hypothesize that the effects of variables $z$ are approximately the same for all countries.

Consider two time intervals during which we observe the indicator $y$. The starting point of the first period is $t 1$ and the end point is $t 2$; the starting and the end points of the second period are $t 3$ and $t 4$, respectively. Let $D 1_{i}=y_{i, t 2}-y_{i, t 1}$ be the change in indicator $y$ over the first period for country $i$, and define $D 1_{j}, D 2_{i}$, and $D 2_{j}$ analogously for the second group of countries and the second time period. If no changes in variables $z$ occurred, the difference $D 1_{i}-D 2_{i}$ would tell us how the reaction of $y$ to $x$ changed as a result of the shift in the policy regime. Because variables $Z$ can change, however, we must compare this change with the same difference for countries in which no regime shift occurred. Thus, the double difference

$$
D D=\frac{1}{N} \sum_{i=1}^{N}\left(D 1_{i}-D 2_{i}\right)-\frac{1}{M} \sum_{j=1}^{M}\left(D 1_{j}-D 2_{j}\right)
$$

gives us a proxy for the impact of the change in policy regime on the response of $y$ to $x$.

\section{Comparing the 1978 and the 1998 Oil Price Hikes: Empirical Results}

We use this method to compare the monetary policy reactions and consequences of the 1978 and 1998 oil price hikes. Specifically, we look at three indicators. The first is the annual CPI inflation rate, our basic indicator of monetary policy outcomes. The second is the change in long-term government bond rates. We take this as a measure of monetary policy credibility, as a large increase in nominal longterm rates indicates rising inflation expectations. The third is the change in short-term money market rates. The increase in short-term rates following an oil price hike indicates the extent of monetary tightening that the central banks perceived to be necessary to control inflation after that rise in oil prices. We use data from six IT countries-Australia, Canada, Chile, New Zealand, Sweden, and the United Kingdom-and four non-IT countries-Denmark, Germany, Switzerland, and the United States. Note that the second episode of rising oil prices spans the beginning of the European Monetary Union on January 1, 1999, which implies a shift of responsibility for monetary policy from the Bundesbank to the European Central Bank (which does not pursue IT). Thus, the case of Germany remains a valid observation in the control group. All data except Sweden's long-term bond rates, Chile's short-term and longterm interest rates, and New Zealand's inflation rates, which were provided by the respective central banks, are taken from the International Monetary Fund's IFS. We use monthly series wherever possible.

The use of the double differences method requires us to choose the dates at which we measure an indicator to calculate its total change during an episode of rising oil prices. The simplest choice would be to take the value of the indicator at the start and at the end of the oil price hike. This, however, could lead to serious measurement bias. Consider CPI inflation. A first point is that changes in oil prices take some time to be passed through to consumer prices. Thus, the CPI inflation rate at the start of the oil price hike is unlikely to be affected by the hike. A second point is that CPI inflation at the start of a period of rising oil prices is affected by economic policies and developments preceding the oil price hike. Taking a too-early measurement of CPI inflation thus runs the risk of using data tainted by the effects of policies predating the episode of interest. Finally, there is likely to be some variation across countries in the appropriate dates 
for measuring the effect of the oil price hike on inflation, as the pass-through and preceding policies will be different across countries. In the case of long-term rates and short-term rates, there is also likely to be some cross-country variation in the time that it took markets to realize that a prolonged oil price hike was happening and in the time that it took central banks to realize this and to decide to take action against the incipient inflationary consequences of those rising oil prices.

In view of these difficulties, we use a common rule for picking observations for all countries and data series rather than the same dates for all countries. For each indicator series, we look for the first valley after the beginning of the episode of rising oil prices, i.e., the lowest realization followed by a string of increases. We then look for the next highest realization followed by a string of declining values for the same series, i.e., the next peak in the time series. We use the difference between the latter and the former to calculate the differences $D 1_{i}$ and $D 1_{j}$ and apply the same procedure for the second episode.

Consider Figure 4B, which shows the inflation rates of Germany, Canada, the United Kingdom, the United States, and Sweden for illustration. The German inflation rate stood at 2.70 percent in July 1978 , the starting month of the oil price hike. It fell to 2.24 percent in November 1978 , which we use as the valley in this episode. Between November 1978 and May 1980, the inflation rate increased to a maximum of 5.94 percent. Thus, $D 1$ is 3.70 percent for Germany. The Swedish inflation rate stood at 8.63 percent in July 1978 and fell to 5.53 percent in February 1979. We use this value as the valley of this episode. Swedish inflation then rose to 13.58 percent in April 1980, resulting in a difference $(D 1)$ of 8.05 percent in this episode. Note that, after several months of lower inflation rates, Swedish inflation eventually peaked at 15.57 percent in October 1980. We do not use that value as the peak to calculate $D 1$, however, as the new increase in inflation might have been due to other influences. If anything, this biases our procedure in the conservative direction. Using similar considerations, we chose September 1978, July 1978, and December 1978 as the valleys for the United Kingdom, the United States, and Canada in this episode, and May 1980, March 1980, and July 1981 as the respective peaks. While the procedure admittedly requires some judgement in some cases, we try to err on the conservative side. In Table 4, we indicate the length of time between the valley and the peak for each indicator considered and each episode.

Table 4A shows our results for inflation rates. The average increase in inflation rates over the first episode amounted to 8.35 percent, considerably more than the 5.37 percent average for the non-IT countries. In the second episode of rising oil prices, the average increase in inflation is 2.99 percent for IT countries. Thus, the average difference in the inflation impact between the two episodes is $D 1-D 2$ $=5.36$ percent. This indicates that the inflation performance of IT countries facing oil price hikes has improved substantially. But note that these gains are distributed quite unevenly. Canada and Australia realized only relatively small improvements, while New Zealand and the United Kingdom enjoyed large ones. The average increase in inflation in the second episode is 1.97 percent among non-IT countries. Thus, $D 1-D 2=3.41$ percent, indicating that the non-IT countries realized improvements in their inflation performance, too. As a result, the double difference is $D D=5.36-3.41=1.95$.

The result thus shows that the IT countries were able to achieve greater improvement in their inflation performance than the non-IT countries. We can conclude, therefore, that the introduction of the new monetary regime helped these countries to improve their inflation performance. However, a conventional $t$ test shows that the difference to the non-IT countries is not statistically different from zero. This is due primarily to the relatively small improvements in inflation performance observed in Canada and Australia.

Now consider the evidence for inflation expectations contained in long-term bond rates (see Table 4B). The average increase in long-term interest rates among the IT group was 5.78 percent. Chile stands out in this group with the largest increase. On average, among the non-IT countries, long-term rates went up by 3.27 percent during the first episode of rising oil prices. The difference between the two groups suggests that non-IT countries enjoyed better monetary policy credibility. In the second episode, the average increase in long-term bond rates was 2.17 percent, signaling a large improvement in credibility. In fact, the average increase in long-term bond rates among the IT countries was only marginally higher than the average increase among the non-IT countries (1.83 percent). The non-IT countries thus experienced an improvement in monetary policy credibility, too, though a more modest one. As a result, the average double difference, $D D$, amounts 


\section{Table 4}

Double Differences

\begin{tabular}{|c|c|c|c|c|c|c|c|c|c|c|}
\hline & Low & High & $D 1$ & Time & Low & High & D2 & Time & D1-D2 & $D D$ \\
\hline \multicolumn{11}{|c|}{ A. CPI inflation rates* } \\
\hline Australia & 5.68 & 11.46 & 5.78 & 15 & 0.42 & 4.46 & 4.02 & 14 & 1.76 & -1.65 \\
\hline Canada & 8.43 & 12.87 & 4.44 & 32 & 0.55 & 3.03 & 2.48 & 13 & 1.96 & -1.45 \\
\hline Chile & 29.68 & 39.22 & 9.54 & 11 & 2.31 & 4.69 & 2.38 & 14 & 7.16 & 3.75 \\
\hline New Zealand & 10.30 & 18.40 & 8.10 & 15 & -0.5 & 4.00 & 4.50 & 15 & 3.60 & 0.19 \\
\hline Sweden & 5.53 & 13.58 & 8.05 & 14 & -1.12 & 1.33 & 2.35 & 12 & 5.68 & 2.27 \\
\hline UK & 7.76 & 21.94 & 14.18 & 32 & 1.10 & 3.31 & 2.21 & 13 & 11.97 & 8.56 \\
\hline Switzerland & 0.4 & 5.16 & 4.76 & 13 & -0.10 & 1.94 & 2.04 & 13 & 2.72 & \\
\hline Denmark & 6.73 & 12.80 & 6.07 & 9 & 1.71 & 3.15 & 1.44 & 13 & 4.63 & \\
\hline Germany & 2.24 & 5.94 & 3.70 & 22 & 0.19 & 2.47 & 2.28 & 19 & 1.42 & \\
\hline US & 7.72 & 14.68 & 6.96 & 20 & 1.61 & 3.76 & 2.10 & 15 & 4.86 & \\
\hline
\end{tabular}

\section{B. Long-term government bond yields ${ }^{\boldsymbol{}}$}

\begin{tabular}{|c|c|c|c|c|c|c|c|c|c|c|}
\hline Australia & 8.80 & 16.50 & 7.70 & 33 & 5.01 & 7.16 & 2.15 & 13 & 5.55 & 4.11 \\
\hline Canada & 9.66 & 13.45 & 3.79 & 11 & 5.08 & 6.38 & 1.30 & 11 & 2.49 & 1.05 \\
\hline Chile & 54.47 & 67.27 & 12.80 & 9 & 11.62 & 16.77 & 5.15 & 2 & 7.65 & 6.21 \\
\hline New Zealand & 9.99 & 13.57 & 3.58 & 15 & 5.27 & 7.28 & 2.01 & 13 & 1.57 & 0.13 \\
\hline Sweden & 9.99 & 13.78 & 3.79 & 31 & 4.02 & 5.92 & 1.90 & 10 & 1.89 & 0.45 \\
\hline UK & 11.68 & 14.70 & 3.02 & 26 & 4.40 & 4.94 & 0.54 & 9 & 2.48 & 1.04 \\
\hline Switzerland & 3.03 & 5.10 & 2.07 & 27 & 2.53 & 4.19 & 1.66 & 13 & 0.41 & \\
\hline Germany & 5.90 & 9.40 & 3.40 & 20 & 3.53 & 5.35 & 1.82 & 13 & 1.58 & \\
\hline US & 8.41 & 12.75 & 4.34 & 9 & 4.65 & 6.66 & 2.01 & 13 & 2.33 & \\
\hline \multicolumn{11}{|c|}{ C. Short-term money market rates } \\
\hline Australia & 6.88 & 17.05 & 10.17 & 38 & 4.72 & 6.24 & 1.52 & 12 & 8.65 & 4.27 \\
\hline Canada & 6.61 & 19.36 & 12.75 & 16 & 4.59 & 5.75 & 1.16 & 13 & 11.59 & 7.21 \\
\hline Chile & 45.59 & 73.13 & 27.54 & 6 & 5.54 & 13.62 & 8.08 & 5 & 19.46 & 15.08 \\
\hline New Zealand & 10.00 & 16.32 & 6.32 & 16 & 4.30 & 6.88 & 2.58 & 16 & 3.74 & -0.64 \\
\hline Sweden & 5.40 & 16.99 & 11.59 & 25 & 3.00 & 4.10 & 1.10 & 17 & 10.49 & 6.11 \\
\hline UK & 8.25 & 17.38 & 9.13 & 21 & 4.56 & 6.00 & 1.44 & 11 & 7.69 & 3.31 \\
\hline Switzerland & 0.03 & 4.90 & 4.67 & 15 & 0.76 & 3.50 & 2.74 & 16 & 1.93 & \\
\hline Denmark & 10.08 & 16.69 & 6.61 & 3 & 3.07 & 5.78 & 2.71 & 10 & 3.90 & \\
\hline Germany & 2.67 & 9.02 & 6.35 & 13 & 2.42 & 4.98 & 2.56 & 17 & 3.79 & \\
\hline US & 7.81 & 17.61 & 9.80 & 21 & 4.63 & 6.54 & 1.91 & 19 & 7.89 & \\
\hline
\end{tabular}

NOTE: Time means number of months between low and high.

*Estimates are based on monthly data except those for Australia and New Zealand, which are based on quarterly data. tData for Denmark were not available. 
to 2.17. Using a t test indicates that this average is significantly different from zero. Thus, we conclude that the introduction of IT has produced significant gains in terms of the credibility of the monetary authorities' commitment to price stability.

Finally, we turn to short-term interest rates (see Table 4C). During the first episode of rising oil prices, central banks in the IT group raised short-term rates, on average, by 12.92 percent. Eliminating Chile from this group, where the increase was much larger than in the other countries, still leaves an average increase in short-term rates in this group of 9.99 percent. In contrast, the average increase among the non-IT group was 6.86 percent in the first episode. In the second episode, IT and non-IT central banks resembled each other much more in the way they tightened monetary policy. Here, the average increase among IT central banks is 2.65 percent, while the average increase among non-IT central banks is 2.48 percent. The difference in the interest rate responses between the first and the second period is thus substantially larger for the IT central banks. The average double difference, $D D=5.89$, is statistically different from zero as indicated by a $t$ test. This result does not change qualitatively if we remove Chile and the United Kingdom from the IT group. Thus, the data suggest that both types of central banks could get through the second episode of rising oil prices with substantially reduced interest rate hikes compared with the first episode. However, IT central banks managed to reduce their response to the increase in oil prices significantly more than non-IT central banks, which reflects the comparatively poor performance of the IT central banks during the first episode.

Pulling these results together, we find that central banks generally managed to cope with the 1998 oil price hike with substantially less inflation than with the price hike starting in 1978. This may be the result of improved energy intensity and a generally greater commitment to price stability on the parts of all central banks. While both groups of central banks enjoyed improvements in credibility, as indicated by the smaller increases in long-term inflation rates, these gains were larger in the case of IT central banks. The observation that the IT central banks had experienced much larger increases in long-term rates during the first episode than non-IT central banks suggests that the introduction of IT allowed them to achieve the same level of credibility as the central banks in our control group. Finally, we note that better inflation performance and improved credibility required less action in terms of driving up short-term rates from all central banks in the second episode compared with the first episode. Here, again, the IT central banks' improvement is significantly larger, and the data suggest that inflation targeting has resulted in an assimilation of central bank responses to those of the central banks in the control group. Altogether, these findings suggest that the new monetary policy regime has affected central bank behavior and credibility more than it has changed inflation outcomes, which have improved for both groups.

\section{INTERPRETATION AND CONCLUSIONS}

In the early 1990s, a number of countries that had been troubled by high inflation since the 1970s adopted inflation targeting as a strategy to bring inflation down to the low levels experienced by Germany and Switzerland. Since then, the new regime has been praised in the literature as a superior concept for monetary policy. In this paper, we have looked at different types of evidence in order to validate this claim. For six IT countries and three non-IT countries and for two sample periods - a pre-IT period (1978-92) and a post-IT period (1993-2001) we have investigated (i) the stability record by examining the volatility of inflation, output gaps, and central banks' interest rates; (ii) the reaction of central banks' interest rate policies to inflation shocks by estimating Taylor rules and unrestricted VARs; and (iii) the policy reactions to large supply shocks by comparing the central banks' reactions to the huge oil price hikes of 1978-79 and 1998-99.

Taken together, the evidence confirms the claim that IT matters. Adopting this policy has permitted IT countries to reduce inflation to low levels and to curb the volatility of inflation and interest rates; in so doing, these banks have been able to approach the stability achieved by the Bundesbank. Thus, IT has helped the former high-inflation countries to achieve a degree of credibility similar to that of the Bundesbank and the Swiss National Bank. Of all IT countries it is the United Kingdom that has performed best even though its target rate of inflation is higher than the inflation targets of most other countries.

While IT has proven an effective strategy for monetary policy, our evidence does not support the claim that it is superior to strategies that focus on monetary aggregates, such as the Bundesbank's 
approach to monetary targeting between 1974 and 1998 , nor even to the Fed's strategy in the 1980s and 1990 s, which focused neither on monetary nor on inflation targets. It is interesting to note in this context that one of the staunchest supporters of inflation targeting, Svensson (2001), has recently endorsed a more moderate "flexible inflation targeting" in which the inflation target serves as a yardstick for the conduct of monetary policy in the medium run. Abstracting from technicalities, the main idea of "flexible IT" does not differ much from the Bundesbank's former monetary policy concept, in which the inflation objective serves to anchor medium-run inflation expectations while short-run operations are guided by an intermediate monetary target.

Reviews of that strategy have long shown that monetary targeting must not be misinterpreted as a rigid rule. Instead, it is well known that the Bundesbank often tolerated deviations of actual money growth from target if doing so seemed compatible with the goal of low inflation rates. For the Bundesbank, monetary targeting fulfilled two important functions (von Hagen, 1999). It served to structure internal monetary policy debates within the Bundesbank and forced monetary policymakers to take into account the inflationary consequences of their actions, especially in times when inflation risks became a growing concern. Furthermore, the discussion of monetary developments served as a framework for an effective dialogue between the bank and the public, which stabilized long-run inflation expectations and helped the bank maintain a relatively steady policy course.

Recent models of IT adopt a similar perspective and stress the importance of the communication tools developed by IT central banks to improve the public's understanding of central bank intentions and to stabilize inflation expectations over the long run (Cukierman, 2000; Faust and Svensson, 2000; Geraarts, 2000). The evidence presented in this paper suggests that the positive impact on inflation expectations has been the most beneficial effect of the new regime. In the same vein, the reductions in short-term volatility of central bank interest rates in the IT countries is compatible with the view that IT has helped monetary policymakers to focus less on transitory, short-term developments and adopt a steadier course of monetary policy. From this perspective, then, IT matters if used effectively to structure policy debates both within the central bank and between the central bank and its public. This interpretation means that IT, like other monetary policy strategies, must be seen in the context of (economic) culture and traditions. Given the central bank's commitment to price stability and its willingness to bind its policy to an intermediate target that serves as the nominal anchor for monetary policy, the choice between an inflation target or a monetary aggregate then is probably more a question of culture than economic principles.

\section{REFERENCES}

Alesina, Alberto F; Blanchard, Olivier; Gali, Jordi; Giavazzi, Francesco and Uhlig, Harald. Defining a Macroeconomic Framework for the Euro Area: Monitoring the European Central Bank 3. London: Centre for Economic Policy Research, 2001.

Ammer, John and Freeman, Richard T. "Inflation Targeting in the 1990s: The Experiences of New Zealand, Canada, and the United Kingdom." Journal of Economics and Business, May 1995, 47(2), pp. 165-92.

Bernanke, Ben; Laubach, Thomas; Mishkin, Frederic and Posen, Adam. Inflation Targeting: Lessons from the International Experience. Princeton: Princeton University Press, 1999.

Cecchetti, Stephen and Ehrmann, Michael. "Does Inflation Targeting Increase Output Volatility? An International Comparison of Policymakers' Preferences and Outcomes." Working Paper 69, Central Bank of Chile, 2000.

Chortareas, Georgios; Stasavage, David and Sterne, Gabriel. "Does It Pay To Be Transparent? International Evidence from Central Bank Forecasts.” Federal Reserve Bank of St. Louis Review, July/August 2002, 84(4), pp. 99-118.

Corbo, Vittorio; Landerretche Moreno, Oscar and SchmidtHebbel, Klaus. "Assessing Inflation Targeting After a Decade of World Experience." Unpublished manuscript, Central Bank of Chile, 2001.

Cukierman, Alex. "Are Contemporary Central Banks Transparent About Economic Models and Objectives and What Difference Does It Make?" Federal Reserve Bank of St. Louis Review, July/August 2002, 84(4), pp. 15-36.

Debelle, G. "Inflation Targeting in Practice." Working Paper 97/35, International Monetary Fund, 1997.

European Central Bank. The Monetary Policy of the ECB. Frankfurt: European Central Bank, 2001. 
Faust, J. and Svensson, Lars E.O. "The Equilibrium Degree of Transparency and Control in Monetary Policy." Working paper, 2000.

Freeman, Richard T. and Willis, Jonathan L. "Targeting Inflation in the 1990s: Recent Challenges." International Finance Discussion Paper 1995-525, Board of Governors of the Federal Reserve System, 1995.

Geraats, Petra. "Why Adopt Transparency? The Publication of Central Bank Forecasts.” Working Paper 41, European Central Bank, 2001.

Gramlich, Edward M. Remarks before the Charlotte Economics Club, 13 January 2001.

Kahn, George A. and Parrish, Klara. "Conducting Monetary Policy with Inflation Targets." Federal Reserve Bank of Kansas City Economic Review, Third Quarter 1998, pp. 5-32.

Kuttner, K.N. and Posen, Adam S. "Does Talk Matter After All? Inflation Targeting and Central Bank Behavior.” Federal Reserve Bank of New York Staff Report, October 1999, 88

Laubach, T. and Posen, Adam S. "Some Comparative Evidence on the Effectiveness of Inflation Targeting." Research Paper 9714, Federal Reserve Bank of New York, 1997.

Leiderman, Leo and Svensson, Lars E.O., eds. Inflation Targets. London: Centre for Economic Policy Research, 1995.

Mishkin, Frederic S. and Posen, Adam S. "Inflation
Targeting: Lessons from Four Countries.” Federal Reserve Bank of New York Economic Policy Review, 1997, pp. 9-117.

Organization for Economic Cooperation and Development. "Comparison of Energy Efficiency in OECD Countries (1970s and 1990s).” Unpublished manuscript, 2001.

Schaechter, Andrea; Stone, Mark R. and Zelmer, Mark. "Adopting Inflation Targeting: Practical Issues for Emerging Market Countries.” Ocassional Paper 202, International Monetary Fund, 2000.

Siklos, Pierre L. "Inflation-Target Design: Changing Inflation Performance and Persistence in Industrial Countries." Federal Reserve Bank of St. Louis Review, March/April 1999, 81(2), pp. 46-58.

Svensson, Lars E.O. "Independent Review of the Operation of Monetary Policy in New Zealand." Unpublished manuscript, 2001.

Taylor, John B. "A Historical Analysis of Monetary Policy Rules," in John B. Taylor, ed., Monetary Policy Rules. Chicago: The University of Chicago Press, 1999, pp. 319-41.

von Hagen, Jürgen. "Inflation and Monetary Targeting in Germany," in Leonardo Leiderman and Lars E.O. Svensson, eds, Inflation Targets. London: Centre for Economic Policy Research, 1995, pp. 107-21.

"Money Growth Targeting by the Bundesbank." Journal of Monetary Economics, 1999, 43, pp. 681-701. 


\section{Appendix}

\section{TAYLOR RULES FOR THE UNITED STATES}

This appendix serves to show that the long-run response of the short-term interest rate to the rate of inflation critically depends on the price index used for measuring inflation.

We begin by reestimating the static equation provided by Taylor (1999) for quarterly U.S. data spanning the period 1987:01-1997:03. The dependent variable is the federal funds rate, the rate of inflation is the year-over-year rate of change of the GDP deflator, and the gap is measured as the percentage deviation of GDP from trend, applying the Hodrick-Prescott filter.

The first regression, shown in Table A1, is Taylor's original estimate, implying the familiar strong response of the funds rate to inflation of 1.5. The following regression, variant (1), serves to show that our data broadly reproduce Taylor's result though the estimated response to inflation is some- what lower. Replacing GDP by industrial production reduces the estimated response for the output gap but provides the same inflation response; see variant (2). Variants (3) and (4), finally, repeat the exercise but employ the rate of inflation as measured by the CPI. This reduces the estimated response to inflation markedly. No longer is it different from unity for the sample period used by Taylor. Similar downward shifts of the estimated inflation response are found for the sample periods used in the text.

Next, we note that the estimates in Table A1 all exhibit very low Durbin-Watson statistics, indicating dynamic misspecification. Table A2 presents dynamic estimates for our subperiods, employing the GDP deflator and the CPI alternatively. These dynamic specifications use the lagged federal funds rate as an additional regressor. Here, we find that the estimated short- and long-run response to inflation is smaller when the CPI index is used instead of the GDP deflator.

\section{Table A1}

Taylor's Static Estimate for 1987:01-1997:03

\begin{tabular}{|c|c|c|c|c|c|c|c|}
\hline & Constant & $\pi_{t}$ deflator & $\mathrm{CPI}$ & $\operatorname{Gap}_{t}$ GDP & IP & $\overline{\mathbf{R}}^{2}$ & DW \\
\hline Taylor & $1.17^{*}$ & $1.53^{* *}$ & & $0.77^{* *}$ & & 0.83 & \\
\hline \multicolumn{8}{|c|}{ Variants } \\
\hline (1) & $2.03^{* *}$ & $1.36^{* *}$ & & $0.93^{* *}$ & & 0.72 & 0.22 \\
\hline (2) & $2.02^{* *}$ & $1.37^{* *}$ & & & $0.62^{* *}$ & 0.81 & 0.23 \\
\hline (3) & $2.31^{* *}$ & & $1.02^{* *}$ & $0.91^{* *}$ & & 0.69 & 0.35 \\
\hline (4) & $2.28 * *$ & & $1.02^{* *}$ & & $0.61^{* *}$ & 0.78 & 0.45 \\
\hline
\end{tabular}

NOTE: $\pi$ is the average inflation rate over four quarters, computed from the GDP deflator or the CPI; Gap is the percentage deviation of output from trend, computed from GDP data or the index of industrial production (IP). * and ${ }^{* *}$ indicate significance at the 5 and 1 percent confidence levels, respectively. 


\section{Table A2}

Dynamic Estimates for Samples 1978:03-1992:02 and 1993:01-2001:01

\begin{tabular}{|c|c|c|c|c|c|c|c|}
\hline & Constant & $\pi_{t}$ deflator & CPI & $\operatorname{Gap}_{t}$ IP & $i_{t-1}$ & $\overline{\mathbf{R}}^{2}$ & $\begin{array}{l}\text { Long-run response } \\
\text { to inflation }\end{array}$ \\
\hline \multicolumn{8}{|l|}{ 1978-92 } \\
\hline (1) & 0.74 & & $0.16^{*}$ & $0.15^{*}$ & $0.81^{* *}$ & 0.85 & 0.87 \\
\hline (2) & 0.82 & $0.35^{* *}$ & & $0.15^{* *}$ & $0.72 * *$ & 0.87 & 1.24 \\
\hline \multicolumn{8}{|l|}{ 1993-01 } \\
\hline (1) & $0.78^{* *}$ & & $0.18^{*}$ & $0.28^{* *}$ & $0.76^{* *}$ & 0.95 & 0.74 \\
\hline (2) & 0.61 & $0.27^{*}$ & & $0.29 * *$ & $0.78^{* *}$ & 0.95 & 1.25 \\
\hline
\end{tabular}

NOTE: $\pi$ is the average inflation rate over four quarters, computed from the GDP deflator or the CPI; Gap is the percentage deviation of industrial production (IP) from trend. ${ }^{*}$ and ${ }^{* *}$ indicate significance at the 5 and 1 percent confidence levels, respectively. 